Article

\title{
Damage Detection of Asphalt Concrete Using Piezo-Ultrasonic Wave Technology
}

\author{
Wen-hao Pan ${ }^{1,2}$, Xu-dong Sun ${ }^{1}$, Li-mei Wu ${ }^{2}$, Kai-kai Yang ${ }^{2}$ and Ning Tang ${ }^{2, *}$ \\ 1 School of Materials Science and Engineering, Northeast University, Shenyang 110819, China; \\ pwh@sjzu.edu.cn (W.-h.P.); sxd@neu.edu.cn (X.-d.S.) \\ 2 School of Materials Science and Engineering, Shenyang Jianzhu University, Shenyang 110168, China; \\ lmwu@sjzu.edu.cn (L.-m.W.); yangkaikai@stu.sjzu.edu.cn (K.-k.Y.) \\ * Correspondence: tangning@sjzu.edu.cn; Tel.: +86-24-24690315
}

Received: 24 December 2018; Accepted: 29 January 2019; Published: 31 January 2019

check for updates

\begin{abstract}
Asphalt concrete has been widely used in road engineering as a surface material. Meanwhile, ultrasonic testing technology has also been developed rapidly. Aiming to evaluate the feasibility of the ultrasonic wave method, the present work reports a laboratory investigation on damage detection of asphalt concrete using piezo-ultrasonic wave technology. The gradation of AC-13 was selected and prepared based on the Marshall's design. The ultrasonic wave velocities of samples were tested with different environmental conditions firstly. After that, the samples were destroyed into two types, one was drilled and the other was grooved. And the ultrasonic wave velocities of pretreated samples were tested again. Furthermore, the relationship between velocity and damaged process was evaluated based on three point bending test. The test results indicated that piezoelectric ultrasonic wave is a promising technology for damage detection of asphalt concrete with considerable benefits. The ultrasonic velocity decreases with the voidage increases. In a saturated water environment, the measured velocity of ultrasonic wave increased. In a dry environment $\left(50{ }^{\circ} \mathrm{C}\right)$, the velocity the ultrasonic waves increased too. After two freeze-thaw cycles, the voidage increased and the ultrasonic velocity decreased gradually. After factitious damage, the wave must travel through or most likely around the damage, the ultrasonic velocity decreased. During the process of three point bending test, the ultrasonic velocity increased firstly and then decreased slowly until it entered into a steady phase. At last the velocity of ultrasonic wave decreased rapidly. In addition, the errors of the results under different test conditions need to be further studied.
\end{abstract}

Keywords: asphalt concrete; damage detection; ultrasonic wave; velocity

\section{Introduction}

Asphalt concrete is a widely used material for roads and pavements owing to its advantages like seamlessness, easiness of repair, high driving comfortability and lower noise. In addition to exposure to harsh environmental elements during service, traffic loads, sunlight, rain and air result in premature failure of pavement by rutting, raveling and cracking. Hence, the inevitable aging of transportation infrastructure create significant security and economic risks. This raises a new concept, preventative maintenance [1-4]. It is an important way for extending the service life of pavement in a cost effective manner. It change the passiveness to positive at the appropriate time.

For pavement maintenance, how to identify the damage and fatigue of pavement and make a cost-effective decision is a difficult task for engineers, especially appropriate time and frequency of maintenance. In the traditional process of evaluating and inspecting, the core samples are always drilled and taken to the laboratory to obtain the corresponding performance through standard test, so that the identify process is complicated and the test period is too long [5-8]. Furthermore, traditional 
maintenance is a passive way to repair the pavement when the pavement structure damage. It is very important to find a way to identify the maintenance time accurately and quickly. Therefore, some new non-destructive testing (NDT) techniques are applied in pavement assessment, such as ground-penetrating radar (GPR), spectral analysis of surface wave (SASW) and ultrasonic testing technology (UT) [9-13].

GPR is an electromagnetic wave method for detecting the internal structure of pavement by using high frequency pulse electromagnetic field, which can provide high resolution 2D and 3D under pavement images $[14,15]$. SASW has been widely used as a non-destructive testing method for underground exploration and geological experiment. The dispersion characteristics of the propagating surface wave in the pavement are measured by the phase difference between the two sensing channels. The dispersion curve is obtained by data transmission. The shape of the pavement and the shear velocity are estimated by the inversion program [16,17]. However, these two methods need to be tested in the field and analyzed in laboratory. Hence, how to realize the complete, fast and automatic recognition of the pavement damage in the field and how to guarantee the high accuracy rate, are the research topic that the relevant scholars need to solve urgently at present.

Ultrasonic testing technology is one of the most widely used nondestructive testing methods. The principle of ultrasonic testing technology is to excite elastic waves in engineering structures or materials through ultrasonic transducers. The elastic waves propagate in materials or structures with various waveforms and another transducer receives them. The characteristic parameters of elastic wave are directly related to the properties of materials or structure such as time, wave velocity, wave amplitude and wave shape.

The application of ultrasonic testing technology is in the rock and cement concrete materials [18,19] but the application in asphalt mixture is not as many [20-25]. The research is still in the exploratory stage, such as the relationship between ultrasonic velocity and airvoid, elastic modulus, fatigue life and so on. Research still needs to supplement more data to improve the research system, so as to achieve qualitative to quantitative transformation.

In this study, the gradation of AC-13 was selected and prepared based on the Marshall's design. The samples included Marshall specimens and beams. The ultrasonic wave velocities of samples were tested with different environmental conditions firstly like wet, dry and freeze-thaw. After that, the samples were destroyed into two types, one was drilled and the other was grooved. The ultrasonic wave velocities of pretreated samples were tested again. Furthermore, the relationship between velocity and damaged process was evaluated based on three point bending test.

\section{Materials and Methods}

\subsection{Materials}

Bitumen, AH-90 paving grade, was obtained from Liaohe Oilfield of Panjin City, China. The physical properties of the bitumen are given in Table 1.

Table 1. Properties of bitumen.

\begin{tabular}{ccccc}
\hline Property & Unit & Results & Technical Requirements & Test [26] \\
\hline Penetration & $\mathrm{dmm}$ & 88.2 & $80-100$ & $\mathrm{~T} 0604$ \\
Ductility & $\mathrm{cm}$ & 127 & $\geq 100$ & $\mathrm{~T} 0605$ \\
Softening point & ${ }^{\circ} \mathrm{C}$ & 49.1 & $\geq 45$ & $\mathrm{~T} 0606$ \\
Density & $\mathrm{g} / \mathrm{cm}^{3}$ & 1.03 & - & $\mathrm{T} 0603$ \\
\hline
\end{tabular}

\subsection{Preparation of Asphalt Concrete}

Gradation of AC-13 was selected and 24 samples were prepared for optimal binder percentage according to Marshall's design. The specimens were cylinders with a diameter of $101.6 \mathrm{~mm}$ and a 
height of $63.5 \mathrm{~mm}$. The passing rate of AC-13 gradation for each sieve is given in Table 2. Depending on the results optimal binder percentage was $4.9 \%$.

Table 2. Aggregate gradation for AC 13.

\begin{tabular}{ccccccccccc}
\hline Sieve Size (mm) & 16 & 13 & 9.5 & 4.75 & 2.36 & 1.18 & 0.6 & 0.3 & 0.15 & 0.075 \\
\hline Passing (\%) & 100 & 94.8 & 77.1 & 48.6 & 30.3 & 22.8 & 16.2 & 11.4 & 7.6 & 6.1 \\
\hline
\end{tabular}

\subsection{Experimental Methods}

- Piezo-ultrasonic velocity test

The ultrasonic velocity test was carried out on TICO tester (Tectus Group, Zurich, Swiss). The testing voltage of ultrasonic wave was $250 \mathrm{~V}$, the testing temperature was $15^{\circ} \mathrm{C}$ and the frequency of ultrasonic wave was $30 \mathrm{kHz}$. Five test areas were selected for each specimen surface and the test results were averaged. In order to avoid the discreteness of collected data, a minimum of ten repeated measurements under the same experimental conditions (statistical sample size) would be necessary. Furthermore, five samples were prepared for each test.

- $\quad$ Computed Tomography

The scan images of asphalt concrete for voidage calculation were analyzed by an X-ray 3D microscope (nanoVoxel-2700, Sanying Precision Instruments Co. Ltd., Tianjin, China).

- $\quad$ Factitious damage

There were two types of factitious damage as shown in Figure 1. One is that a cylindrical through-hole of $5 \mathrm{~mm}$ diameter was drilled in the Marshall specimen.

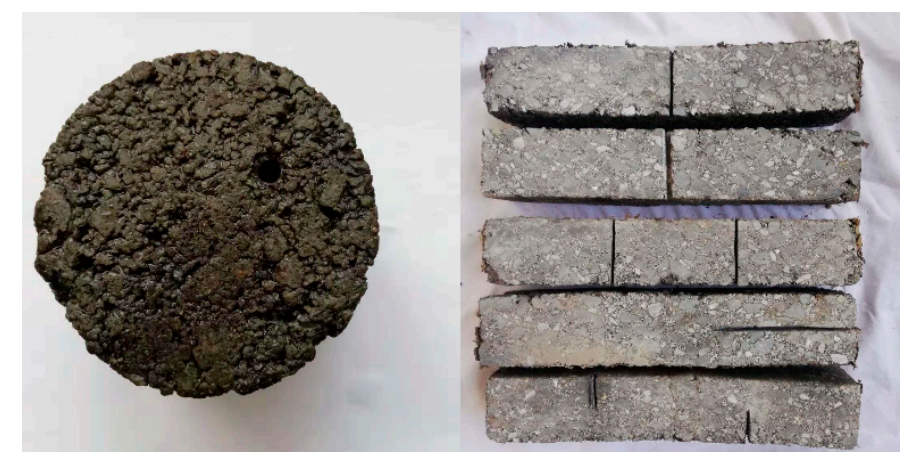

Figure 1. The factitious damage of specimens.

The other is that some grooves with different width were carved on the surface of asphalt beam but the depth of grooves was same, $15 \mathrm{~mm}$. So there are five types of asphalt beam with different grooves as following: groove of $2 \mathrm{~mm}(\mathrm{G}-2 \mathrm{~mm})$, groove of $4 \mathrm{~mm}(\mathrm{G}-4 \mathrm{~mm})$, two grooves of $2 \mathrm{~mm}$ (DG-2 mm), vertical groove of $2 \mathrm{~mm}(\mathrm{VG}-2 \mathrm{~mm}$ ) and half double groove of $2 \mathrm{~mm}$ (HG-2 mm).

- $\quad$ Drying and water-saturated test

The drying test is that all the samples were placed in an oven at $50{ }^{\circ} \mathrm{C}$ for $24 \mathrm{~h}$. The water-saturated test is that all the samples were immersed in water for $24 \mathrm{~h}$. The ultrasonic velocity of samples were measured directly after the environmental pretreatment.

- $\quad$ Freeze-thaw cycle 
There were two cycles. All the samples were full immersed in water for half an hour first and then kept vacuum saturation state for $15 \mathrm{~min}$. After pretreatment, the samples were frozen in the refrigerator at $-18{ }^{\circ} \mathrm{C}$ for $16 \mathrm{~h}$ and then took them out and placed in a bath box at $60^{\circ} \mathrm{C}$ for melting $6 \mathrm{~h}[26]$.

- $\quad$ Three point bending test

The three point bending test was carried out on a material testing machine (WDW-T200, Tianchen, Jinan, China). The distance between the two fulcrums was $200 \mathrm{~mm}$ and the loading point was located at the center of the specimen in length direction. The test was carried out at a dead loading rate of $0.2 \mathrm{kN} / \mathrm{s}$. At the same time, the ultrasonic wave detector was applied to monitor the travel velocity in the specimen in real time until the specimen was damaged.

- Healing

After heating, the bitumen was coated on the cross section of the asphalt beam and then the two cross section were quickly bonded together. At last the healed asphalt beams were placed in an oven at $50{ }^{\circ} \mathrm{C}$ for one hour.

\section{Results and Discussion}

\subsection{Ultrasonic Test}

As a key factor, air voids has been paid much attention due to it is closely related to the road performance. The pavement with larger voidage has better structure depth, anti-skid performance and friction coefficient but the performance of anti-seepage, anti-freezing and anti-moisture is poor. Therefore, to establish the relationship between voidage and piezoelectric ultrasonic velocity is the first prerequisite for using piezoelectric ultrasonic technology. Based on the same gradation, different compaction temperature is used to control the voidage of asphalt concrete. The relationship between voidage and ultrasonic velocity are shown in Figure 2.

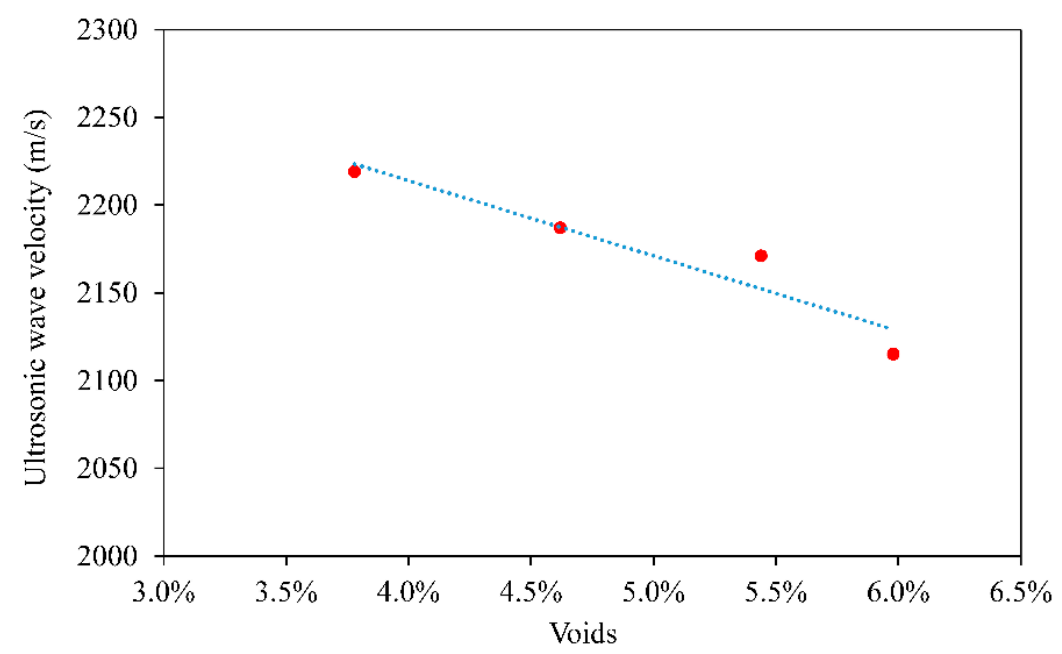

Figure 2. Relationship between ultrasonic wave velocity and voidage of the Marshall samples.

In Figure 2, the data points and trend line show the relationship between the ultrasonic wave velocity and the voidage of the Marshall samples. It is well known that the lower the compaction temperature, the higher the voidage. The voidage was $3.78 \%, 4.62 \%, 5.44 \%$ and $5.98 \%$, respectively. Furthermore, the ultrasonic velocity decreased with the voidage increased. Obviously, there are a lot of voids in the asphalt mixture and the wave travels much faster in the air than in the aggregate, the higher the porosity, the smaller the velocity. In addition, the dispersion of the longitudinal wave was larger due to the high voidage, resulting in long travel time of ultrasonic wave and low wave velocity. 
Usually the voidage of AC-13 asphalt concrete is controlled at 4-6\%. In the following tests, the voidage of all Marshall specimens were controlled at $4.5 \%$ by compaction temperature. The ultrasonic velocities of Marshall specimens with different environmental conditions show in Figure 3.

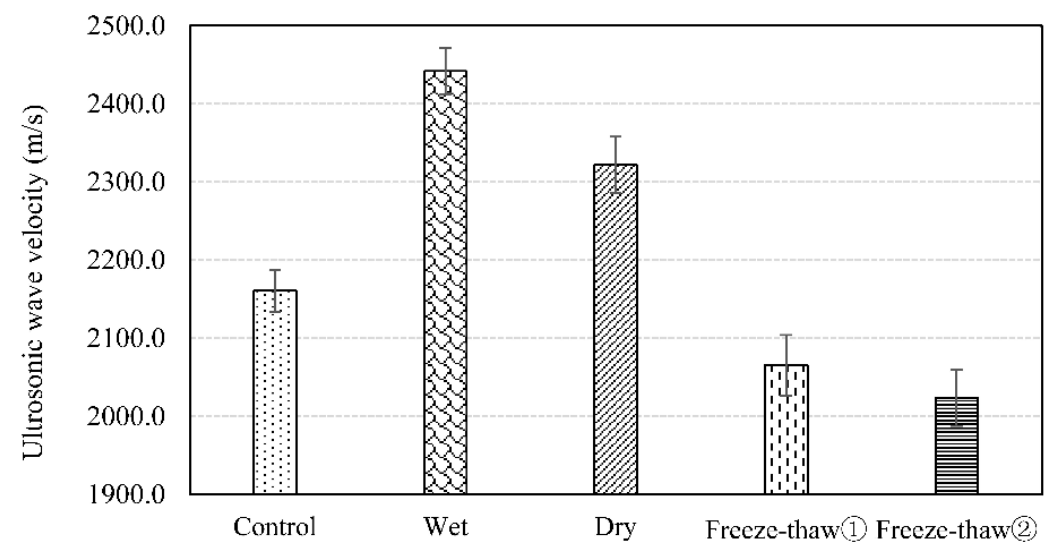

Figure 3. Ultrasonic velocity of Marshall specimens with different environmental conditions.

In a saturated water environment, the average velocity of specimens was $2442 \mathrm{~m} / \mathrm{s}$. The reason is that the water in the pores increases and the pores are basically filled with water. In addition, the velocity of ultrasonic wave propagation in water was much faster than that in air. The increase of water caused the measured wave velocity to become bigger.

In a dry environment $\left(50^{\circ} \mathrm{C}\right)$, the average velocity of specimens was $2321 \mathrm{~m} / \mathrm{s}$. This data was higher than that of the control group and lower than that of the saturated environment. For bitumen, the higher the temperature is, the more obvious the viscoelasticity is. In addition, the dry temperature is higher than the softening point of bitumen. The ultrasonic waves face a greater viscous resistance and the interference and resistance to the propagation of ultrasonic waves are bigger.

Furthermore, the velocity decreased in turn after two freeze-thaw cycles. Bitumen shows viscoelasticity at high temperature and elasticity at low temperature and occurrence of aging in the repeated process of high temperature and low temperature. In addition, the voids of asphalt concrete is occupied by water in the saturation environment. When water freezes, it becomes larger in volume instead of smaller and there is not enough void volume to accommodate the increased volume, so the expansion stress is generated in the void, so that the voidage increased and the ultrasonic velocity decreased gradually and the asphalt mixture was damaged at last.

\subsection{Damage Detection}

All the tests were repeated after the Marshall specimens had been drilled. The ultrasonic data collection included five receiver positions (P1 to P5) for one generator position (P0). Obviously, the distance at which the ultrasound wave travels was different and symmetrical, except P3, due to the damage. The test results show in Figure 4.

Figure 4 shows typical traces for an ultrasonic velocity at different receiver positions. For different environment, the collected ultrasonic data at each receiver position were similar to the data before the samples were damaged. The velocity increases under saturated and dry conditions and decreases after freeze-thaw cycles. In addition, with the increase of the wave travel length, the velocity of the ultrasonic wave in the dry environment increases rapidly, the maximum data is $4027 \mathrm{~m} / \mathrm{s}$.

For different receiver, the wave moved from generator P0 to receiver P4, P2 and P1, the velocity increased (the travel lengths also increase). At receiver P1, the velocity of all samples further increased. On the symmetrical side with the damage, similarly the plot of the average measured velocities showed a dip in the measured velocity caused by the presence of damage. Note that as the velocity of receiver P3 was slower than that of $\mathrm{P} 2$ and the trends of average velocity were expected. This is clearly because the wave must travel through or most likely around the damage. 


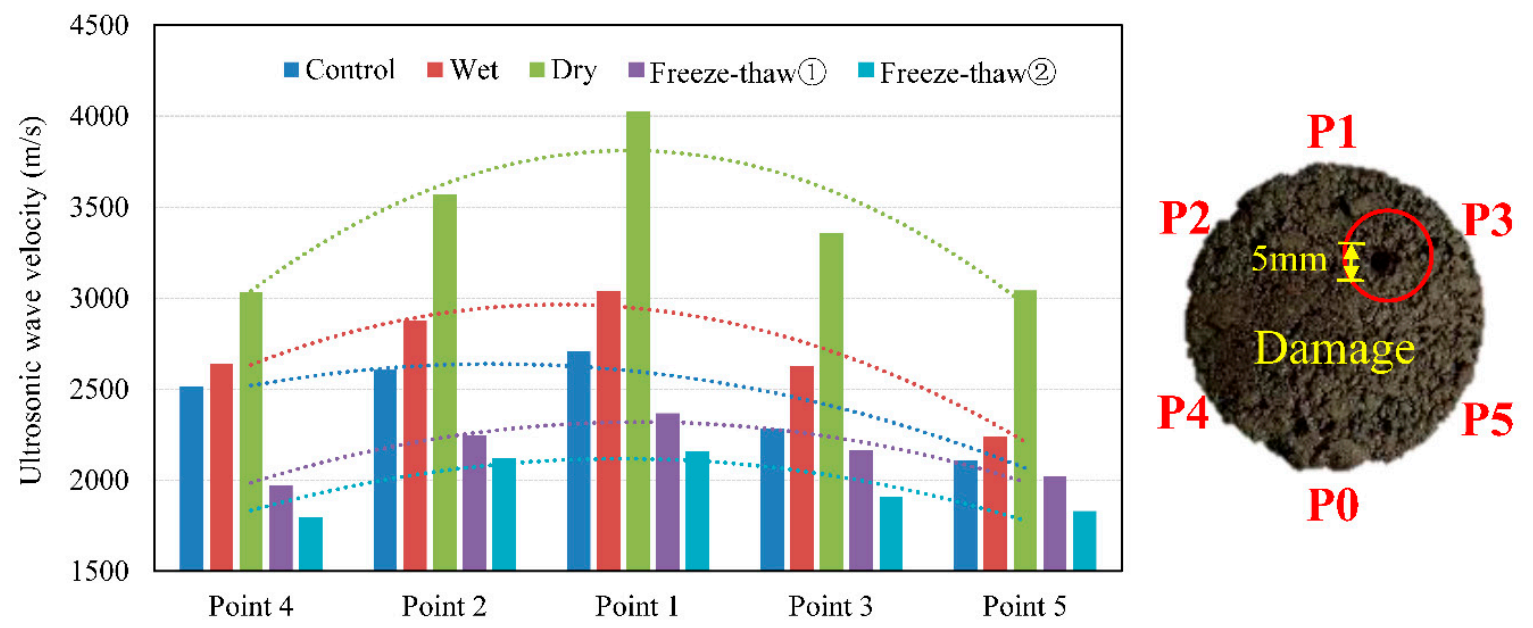

Figure 4. Ultrasonic velocity with different environmental conditions after factitious damage.

But the contact between side surface of the cylinder specimen and the sensor probe is not a complete contact but a linear contact. It can result in minor inaccuracies. To further study the influence of cracks on the velocity of ultrasonic waves, four types of grooves are carved on the different asphalt beam specimens. Figure 5 shows the test results of velocity with simulated cracks.
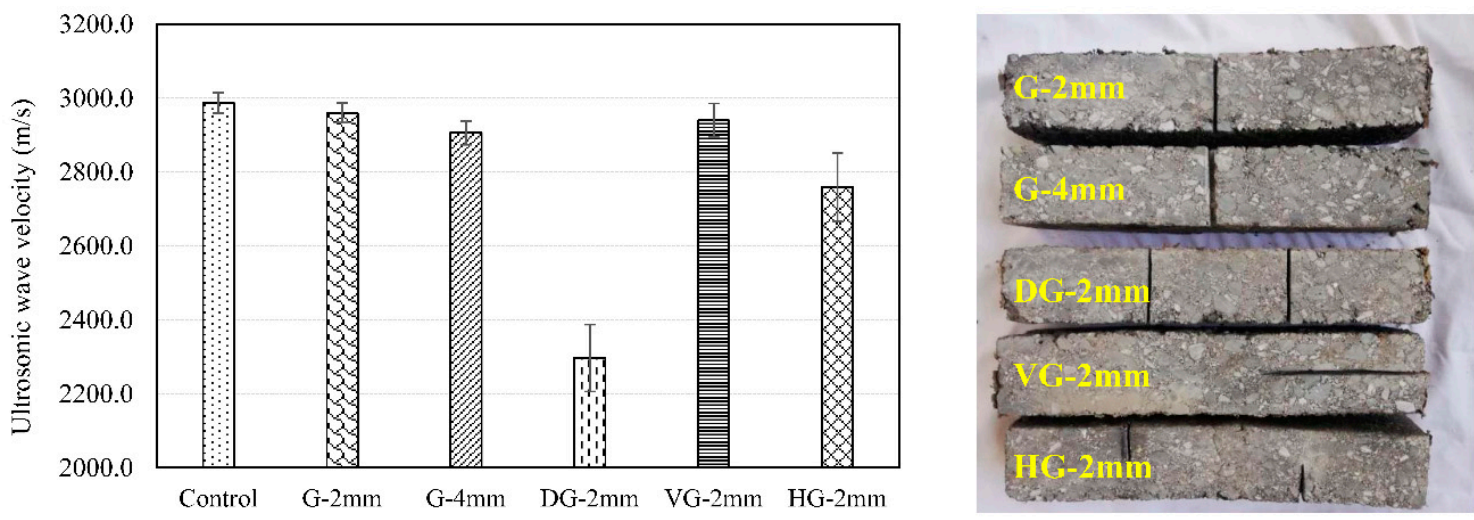

Figure 5. The velocity of ultrasonic waves with five types of grooves.

In Figure 5, for cracks width, ultrasonic velocity slightly decreased when $1 \mathrm{~mm}$ grooves appear on the surface of asphalt concrete beam specimens. But when the crack width increases to $2 \mathrm{~mm}$, the ultrasonic velocity decrease more. Note that the effect of fine cracks on ultrasonic velocity is slight and the ultrasonic velocity decreased with the increased of crack width.

Furthermore, with the presence of two grooves, the ultrasonic velocity decreased obviously and the deviation of the test results was $90.74 \mathrm{~m} / \mathrm{s}$, which was very large. When an ultrasonic wave passed through a crack, only part energy was transmitted and the air inside the crack attenuated the ultrasonic wave. When the ultrasonic wave passed through the next crack, the velocity decreased even more. In addition, the anisotropic property of asphalt concrete makes the instability of the results. Because even if the grooves were in the same position, the aggregate and bitumen content of different bitumen concrete beams were also different at the grooves.

Moreover, the two grooves have been halved. The test produced the velocity of ultrasonic wave ranging from one groove to two grooves. But the deviation of results was $93.21 \mathrm{~m} / \mathrm{s}$, which was very large, too. It revealed that there are significant positive correlations among simulated crack length, simulated crack position and ultrasonic velocity.

At last, asphalt pavement damage has not only transverse crack but also longitudinal crack. One groove was carve on the surface of asphalt beam as simulated vertical crack. The result shows the 
ultrasonic velocity decreased slightly. Hence, when the travel direction of ultrasonic wave was parallel to the crack direction, the change of ultrasonic velocity was slight.

\subsection{Three Point Bending Test}

Three-point bending test is one of the methods to evaluate the fatigue and damage of asphalt concrete. The velocity of ultrasonic wave was measured when asphalt beam specimens were applied a load until failure. Figure 6 shows the change trend of ultrasonic velocity during the whole process of damage. In Figure 6, according to the slope of curve, the damage process of asphalt beam can essentially be broken down into four phases: loading, crack growth, balance and damage.

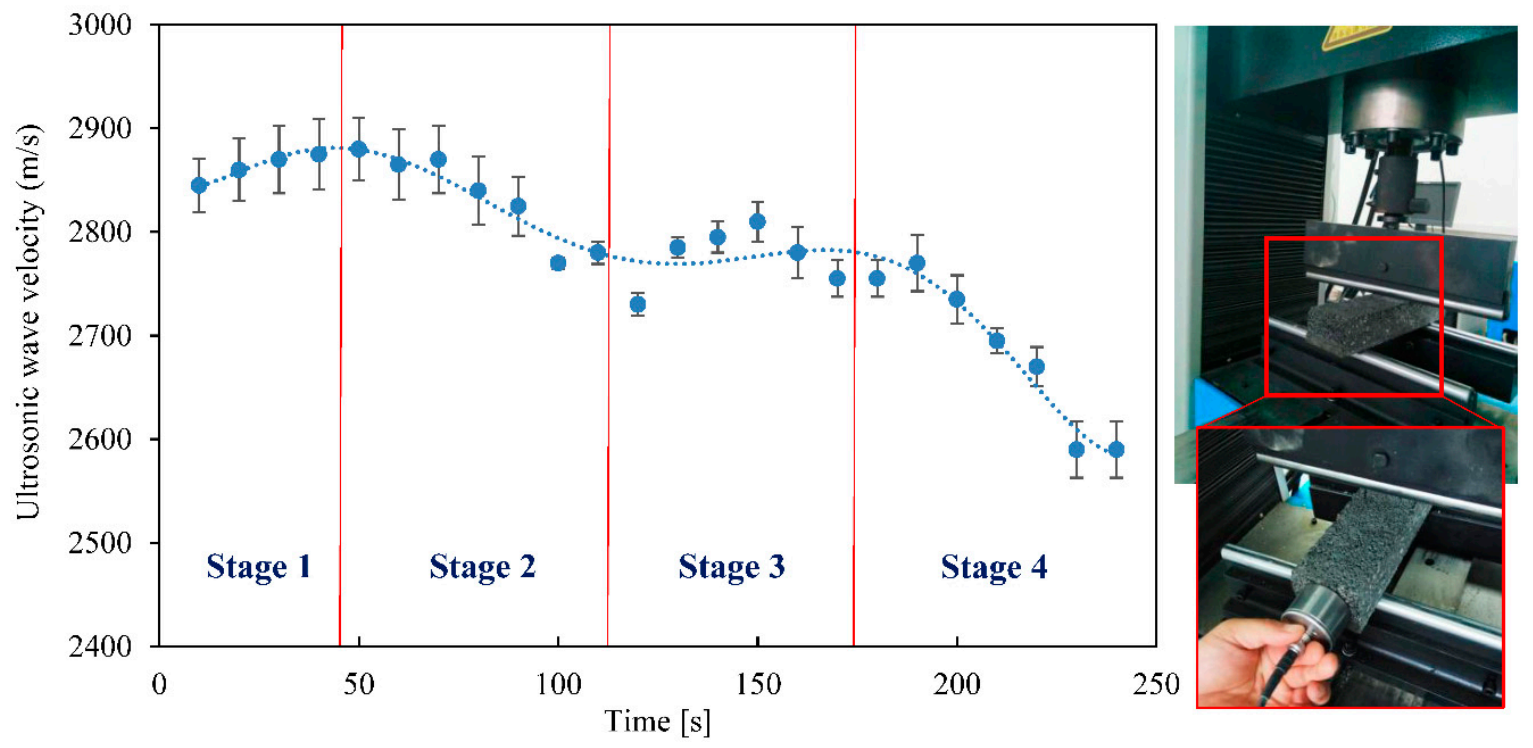

Figure 6. The change trend of ultrasonic velocity during the whole process of damage.

In the stage 1, the ultrasonic velocity increased firstly. In the first $50 \mathrm{~s}$, the ultrasonic velocity increased slightly, because the flexural-tensile stress was applied to the asphalt beam, the travel lengths of ultrasonic wave increased. In addition, asphalt mixture is a typical heterogeneous material. Although the interface conditions between aggregate and bitumen is good, the mechanical properties of these two materials are different, so the deformation of asphalt mixture is very complex. Moreover the voids in the asphalt mixture occurred about $4.5 \%$ of the volume and these voids were crowded during the loading process.

In the stage 2, with the time increase (50 s to $100 \mathrm{~s}$ ), the velocity of ultrasonic wave decreased slowly due to presence of some micro-cracks in the asphalt concrete beam. The growth rate of micro-cracks was higher than the compacted rate of the voids in asphalt concrete beam.

In the stage 3, after $100 \mathrm{~s}$, the velocity of the ultrasound wave barely changed and it had entered into a steady phase. This is clearly because the displacement of the aggregate and bitumen is caused by the deformation of asphalt beam at the same time. And the growth rate of micro-cracks was close to the compacted rate of the voids.

In the stage 4 , the velocity of ultrasonic wave decreased rapidly after $170 \mathrm{~s}$. The micro-crack width increased visibly and cracks appeared on both sides of the larger aggregate at the lower edge of the asphalt beam. The crack grew to the critical state of penetrating and then the asphalt beam was damaged.

In addition, the velocity of ultrasonic wave in the width travel direction of the asphalt beam was measured before and after the three-point bending test. Moreover, the damaged asphalt beam was coated with new bitumen and heated up for healing. All the results were showed in Figure 6.

In Figure 7, with the increase of received length, the velocity of ultrasonic wave decreased one by one in any case. In addition, the damaged asphalt beam cannot receive ultrasonic wave at the receiving 
point $\mathrm{P} 4$ but the ultrasonic wave can be detected again after healing. It indicates that ultrasonic testing technology can be used to detect the cracking state of asphalt concrete effectively.
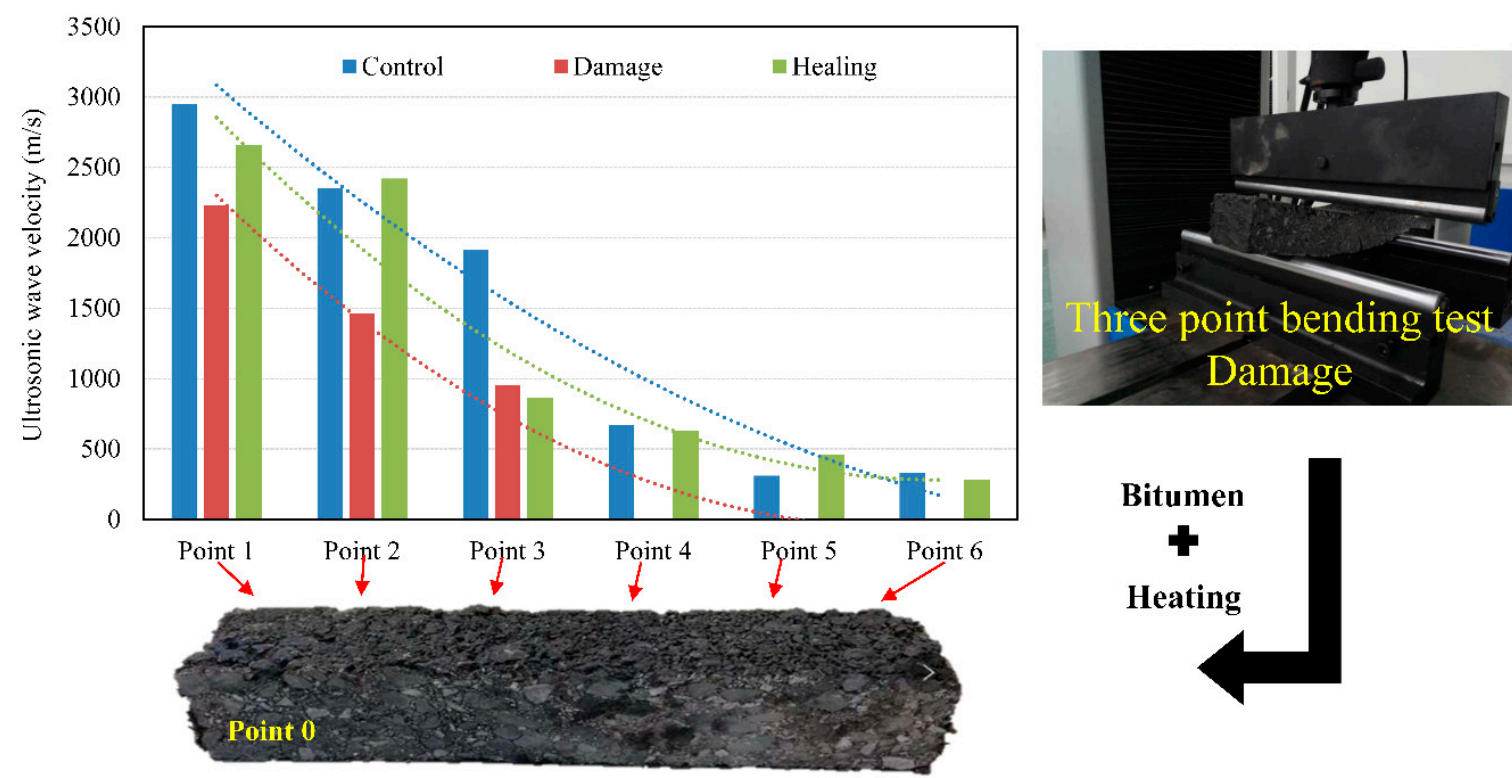

Figure 7. The velocity of ultrasonic wave in the width travel direction of the asphalt beam.

\subsection{Impact Analysis}

Asphalt mixture is a typical heterogeneous material, so different measured positions, different results. In order to analyze the errors, the Marshall specimens were cut into a cube with a length of $5 \mathrm{~cm}$ on the side. This size is close to the size of the piezoelectric ultrasonic probe. The CT scan images are shown in Figure 8. Through the calculation of image processing software (nanoVoxel-2700 system), the voidage of three specimens is $4.08 \%$ (A), $4.32 \%$ (B) and $4.56 \%$ (C), respectively.

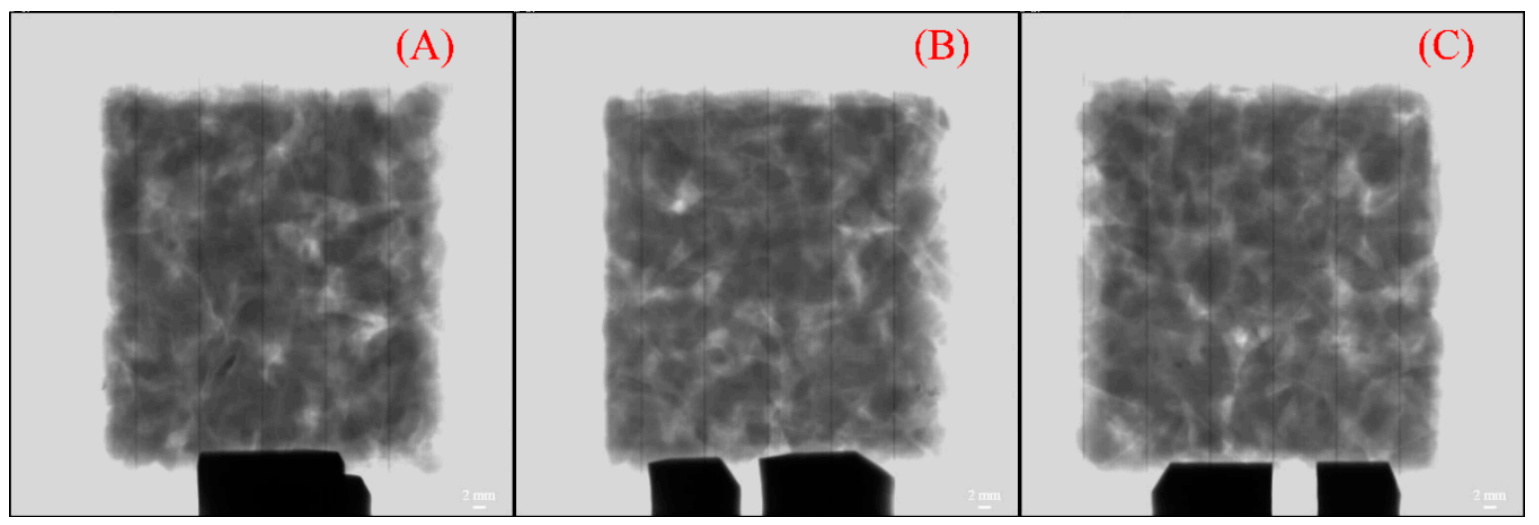

Figure 8. The CT images of cube samples with different voidage: (A) $4.08 \%$, (B) $4.32 \%$, (C) $4.56 \%$.

The ultrasonic velocity of three specimens was $2275 \mathrm{~m} / \mathrm{s}, 2221 \mathrm{~m} / \mathrm{s}$ and $2189 \mathrm{~m} / \mathrm{s}$, respectively. The relationship between velocity and voidage remains unchanged but the value was lower than that of the Marshall specimen. Hence, voidage, temperature sensitivity, viscoelasticity, travel length of ultrasonic wave in asphalt concrete and the size of specimens are main factors affecting the ultrasonic velocity.

Compared with other studies, the ultrasonic velocity is lower than $3000 \mathrm{~m} / \mathrm{s}$ in ambient [21-25]. Based on the impact analysis, it reveals that the ultrasonic velocity is the result of the combined effect of temperature, environment condition and service time. Furthermore, it is still contingency because 
of the reflection, attenuation, resonance and changes of velocity that occurred in an object when the propagation of ultrasonic wave. Hence the research requires a variety of supplementary data. The results of this paper are a useful supplement.

\section{Conclusions}

This study has indicated that piezoelectric ultrasonic wave is a promising technology for damage detection of asphalt concrete with considerable benefits. The test results demonstrated that the ultrasonic velocity decreased with the voidage increases. Furthermore, the increase of humidity and temperature lead to an increase of ultrasonic velocity. Oppositely, after two freeze-thaw cycles, the voidage increased and the ultrasonic velocity decreased gradually.

For factitious cylinder damage, the velocity of ultrasonic wave decreased at damaged position. For factitious groove damage, ultrasonic velocity decreased slightly with the increased of crack width but decreased obviously with the increased of crack quantity. In addition, the change of ultrasonic velocity was slight when the travel direction of ultrasonic wave was parallel to the crack direction.

For the relationship between ultrasonic velocity and the damaged process of asphalt beam, the damaged process can essentially be broken down into four phases: loading, crack growth, balance and damage. Correspondingly, the ultrasonic velocity increased firstly and then decreased slowly until it entered into a steady phase. At last the velocity of ultrasonic wave decreased rapidly.

In addition, voidage, temperature sensitivity, viscoelasticity, travel length of ultrasonic wave in asphalt concrete and the size of specimens are main factors. The errors of the results under different test conditions need to be further studied.

Author Contributions: Conceptualization, W.-h.P. and N.T.; Data curation, W.-h.P., L.-m. W., K.-k.Y. and N.T.; Funding acquisition, L.-m.W. and N.T.; Investigation, W.-h.P., K.-k.Y. and N.T.; Methodology, X.-d.S. and N.T.; Software, W.-h.P. and N.T.; Writing, W.-h.P., X.-d.S., L.-m.W., K.-k.Y. and N.T.

Funding: This research was funded by [National Natural Science Foundation of China] grant number [51508344], [China Postdoctoral Science Foundation] grant number [2016M591458], [Liaoning BaiQianWan Talents Program] grant number [2019] and [Support Plan for innovative talents of Liaoning Province] grant number [201954].

Acknowledgments: Thanks for Science Program and Discipline Content Education Project of Shenyang Jianzhu University. Special thanks Hong Kong Scholar Program and China Scholarship Council for sponsoring a technical visit to Politecnico di Milano.

Conflicts of Interest: The authors declare no conflict of interest.

\section{References}

1. Peshkin, D.G.; Hoerner, T.E.; Zimmerman, K.A. Optimal timing of pavement preventive maintenance treatment applications. J. Transp. Res. Board 2004, 523, 10-15.

2. Giustozzi, F.; Crispino, M.; Flintsch, G.W. Multi-attribute life cycle assessment of preventive maintenance treatments on road pavements for achieving environmental sustainability. Int. J. Life Cycle Assess. 2012, 17, 409-419. [CrossRef]

3. Haider, S.; Dwaikat, M. Estimating optimum timing for preventive maintenance treatment to mitigate pavement roughness. J. Transp. Res. Board 2011, 2235, 43-53. [CrossRef]

4. Chou, J.S.; Le, T.S. Reliability-based performance simulation for optimized pavement maintenance. Reliab. Eng. Syst. Saf. 2011, 96, 1402-1410. [CrossRef]

5. Maierhofer, C.; Arndt, R.; Röllig, M.; Rieck, C.; Walther, A.; Scheel, H.; Hillemeier, B. Application of impulse-thermography for non-destructive assessment of concrete structures. Cem. Concr. Compos. 2006, 28, 393-401. [CrossRef]

6. Winston, R.J.; Al-Rubaei, A.M.; Blecken, G.T.; Viklander, M.; Hunt, W.F. Maintenance measures for preservation and recovery of permeable pavement surface infiltration rate-The effects of street sweeping, vacuum cleaning, high pressure washing, and milling. J. Environ. Manag. 2016, 169, 132-144. [CrossRef] [PubMed]

7. Shah, Y.U.; Jain, S.S.; Parida, M. Evaluation of prioritization methods for effective pavement maintenance of urban roads. Int. J. Pavement Eng. 2014, 15, 238-250. [CrossRef] 
8. Meneses, S.; Ferreira, A. Pavement maintenance programming considering two objectives: Maintenance costs and user costs. Int. J. Pavement Eng. 2013, 14, 206-221. [CrossRef]

9. Usamentiaga, R.; Venegas, P.; Guerediaga, J.; Vega, L.; Molleda, J.; Bulnes, F. Infrared thermography for temperature measurement and non-destructive testing. Sensors 2014, 14, 12305-12348. [CrossRef]

10. Hoła, J.; Bień, J.; Schabowicz, K. Non-destructive and semi-destructive diagnostics of concrete structures in assessment of their durability. Bull. Pol. Acad. Sci. Tech. Sci. 2015, 63, 87-96. [CrossRef]

11. Dumoulin, J.; Ibos, L.; Marchetti, M.; Mazioud, A. Detection of non-emergent defects in asphalt pavement samples by long pulse and pulse phase infrared thermography. Eur. J. Environ. Civ. Eng. 2011, 15, 557-574. [CrossRef]

12. Fauchard, C.; Beaucamp, B.; Laguerre, L. Non-destructive assessment of hot mix asphalt compaction/density with a step-frequency radar: Case study on a newly paved road. Near Surf. Geophys. 2015, 13, 289-297. [CrossRef]

13. Hunaidi, O. Evolution-based genetic algorithms for analysis of non-destructive surface wave tests on pavements. NDT E International 1998, 31, 273-280. [CrossRef]

14. Liu, H.; Sato, M. In situ measurement of pavement thickness and dielectric permittivity by GPR using an antenna array. NDT E Int. 2014, 64, 65-71. [CrossRef]

15. Mai, T.C.; Razafindratsima, S.; Sbartaï, Z.M.; Demontoux, F.; Bos, F. Non-destructive evaluation of moisture content of wood material at GPR frequency. Construct. Build. Mater. 2015, 77, 213-217. [CrossRef]

16. Kumar, J.; Rakaraddi, P.G. SASW evaluation of asphaltic and cement concrete pavements using different heights of fall for a spherical mass. Int. J. Pavement Eng. 2013, 14, 354-363. [CrossRef]

17. Hazra, S.; Kumar, J. SASW testing of asphaltic pavement by dropping steel balls. Int. J. Geotech. Eng. 2014, 8, 34-45. [CrossRef]

18. Rao, S.K.; Sravana, P.; Rao, T.C. Experimental studies in Ultrasonic Pulse Velocity of roller compacted concrete pavement containing fly ash and M-sand. Int. J. Pavement Res. Technol. 2016, 9, 289-301. [CrossRef]

19. Mandal, T.; Tinjum, J.M.; Edil, T.B. Non-destructive testing of cementitiously stabilized materials using ultrasonic pulse velocity test. Transp. Geotech. 2016, 6, 97-107. [CrossRef]

20. Hoegh, K.; Khazanovich, L.; Maser, K.; Tran, N. Evaluation of ultrasonic technique for detecting delamination in asphalt pavements. J. Transp. Res. Board 2012, 2306, 105-110. [CrossRef]

21. Van Velsor, J.K.; Premkumar, L.; Chehab, G.; Rose, J.L. Measuring the Complex Modulus of Asphalt Concrete Using Ultrasonic Testing. J. Eng. Sci. Technol. Rev. 2011, 4, 160-168. [CrossRef]

22. Mounier, D.; Di Benedetto, H.; Sauzéat, C. Determination of bituminous mixtures linear properties using ultrasonic wave propagation. Construct. Build. Mater. 2012, 36, 638-647. [CrossRef]

23. Cheng, Y.; Zhang, P.; Jiao, Y. Damage Simulation and Ultrasonic Detection of Asphalt Mixture under the Coupling Effects of Water-Temperature-Radiation. Adv. Mater. Sci. Eng. 2013, 2013, 1-9. [CrossRef]

24. Tigdemir, M.; Kalyoncuoglu, S.F.; Kalyoncuoglu, U.Y. Application of ultrasonic method in asphalt concrete testing for fatigue life estimation. NDT E Int. 2004, 37, 597-602. [CrossRef]

25. Norambuena, J.; Castro, D. Dynamic modulus of asphalt mixture by ultrasonic direct test. NDT E Int. 2010, 43, 629-634. [CrossRef]

26. Ministry of Transport of China. Standard Test Methods of Bitumen and Bituminous Mixtures for Highway Engineering: JTG E20-2011; Ministry of Transport of China: Beijing, China, 2011.

(C) 2019 by the authors. Licensee MDPI, Basel, Switzerland. This article is an open access article distributed under the terms and conditions of the Creative Commons Attribution (CC BY) license (http:/ / creativecommons.org/licenses/by/4.0/). 